\title{
Isolation and characterization of human polyreactive pneumococcal polysaccharide antibodies
}

\author{
Rebecca S. Thompson ${ }^{1}$, Noor M. Khaskhely ${ }^{1}$, Kristin R. Malhotra ${ }^{1}$, David J. Leggat ${ }^{1}$, \\ Jason Mosakowski ${ }^{1}$, Sadik Khuder ${ }^{1}$, Gary R. McLean ${ }^{3}$, M. A. Julie Westerink ${ }^{1,2^{*}}$ \\ ${ }^{1}$ Department of Medicine, University of Toledo, Toledo, USA; ${ }^{\text {Corresponding Author: mwesterink@,utoledo.edu }}$ \\ ${ }^{2}$ Department of Medical Microbiology and Immunology, University of Toledo, Toledo, USA \\ ${ }^{3}$ School of Human Sciences, London Metropolitan University, London, UK
}

Received 23 April 2012; revised 22 May 2012; accepted 17 July 2012

\section{ABSTRACT}

Natural antibodies serve as the body's first line of defense against pneumococcal challenge. Polyreactive human pneumococcal polysaccharide IgG antibodies have not been extensively studied. We analyzed human polyreactive antibodies that bind multiple pneumococcal polysaccharides, including PPS14 and PPS23F. These antibodies were isolated from single pneumococcal polysaccharide specific B cells allowing for the analysis of human immunoglobulins with natively paired variable regions. Although isolated individually, these antibodies demonstrated similar characteristics. Most antibodies possessed a variable light chain with a CDR3 length made up of nine amino acids and relatively high number of flexible amino acids in combined VH/VL. While these antibodies were polyreactive and structurally alike, kinetic analysis revealed unique $K_{D}$ values. Variable chains are responsible for antigen recognition whereas antibody fine specificity is affected by isotype structure. To investigate the contribution of the constant region of these isotypes and their effect on antibody avidity to pneumococcal polysaccharide, the polyreactive variable regions were expressed as IgG1 or IgG2 and subjected to kinetic analysis. The IgG1 antibodies uniformly had a stronger avidity to PPS14 and PPS23F compared to IgG2. To further document the importance of the constant region in antibody avidity and fine specificity, analysis of antibody $F(a b) ' 2$ fragment binding to PPS14 and PPS23F resulted in similar $K_{D}$ values. These studies suggest that antigen recognition by polyreactive antibodies is determined by a conserved variable light chain CDR3 length and longer, more flexible variable heavy CDR3s when compared to pneumococcal polysaccharide-specific sequences while differences in specific avidities are modulated by antibody isotype.

Keywords: B Cell; Pneumococcal Polysaccharide; Polyreactive; Natural; Isotype

\section{INTRODUCTION}

Streptococcus pneumoniae is a human bacterial pathogen that colonizes the nasopharynx and is a major cause of pneumonia, meningitis and acute otitis media $[1,2]$. The main virulence factor of $S$. pneumoniae is the capsular polysaccharide [3]. Antibodies against pneumococcal polysaccharide (PPS) provide protection against disease. Natural or nonspecific antibodies are believed to provide a first line of defense against pneumococcal invasion. These antibodies are part of the early phase of the immune reaction and protect against infection and/or decrease the bacterial load if infection is already present [4]. Little is known about inherent human nonspecific PPS antibodies. It is thought that human polyreactive antibodies are selected into the marginal zone B cell compartment, as demonstrated in immunoglobulin (Ig) transgenic mice [5-8].

Murine studies have identified a B cell subset responsible for the production of these antibodies. B1a cells are a distinct population characterized by the CD5 surface marker [4]. B1a cells spontaneously secrete low avidity, polyreactive antibodies against PPSs and other antigens. Experimental evidence has suggested that the B1 cell population decreases with age possibly contributing to disease susceptibility [9].

We isolated PPS-binding single B cells and several B cell clones were identified that bound multiple PPSs. The goal of this study was to explore the structural and kinetic characteristics of isolated polyreactive human PPS antibodies. Furthermore, we analyzed the role of the an- 
tibody constant region by comparing avidity values for variable heavy and variable light (VH/VL) pairs expressed as IgG1, IgG2 and F(ab)'2.

\section{MATERIALS AND METHODS}

\subsection{Human Volunteers and Vaccination}

Healthy young adult volunteers (18 to 30 years old) participated in this study. Volunteers were recruited from the student population at the University of Toledo Health Science Campus (Toledo, $\mathrm{OH}$ ). Each volunteer was questioned concerning previous pneumococcal vaccinetion, medications, previous illness, and present health. In addition, we obtained complete blood count (CBC); a comprehensive chemistry profile; total B cells; T-cell subsets; and total immunoglobulin G (IgG), IgM, and IgA levels. Individuals previously immunized with the pneumococcal vaccine and any individual considered to be immunocompromised did not qualify. Informed consent was obtained from all participants using protocols reviewed and approved by the Institutional Review Board at the University of Toledo.

\subsection{Pneumococcal Polysaccharide ELISA}

The pneumococcal polysaccharide ELISA is a modification of the WHO assay [10]. Briefly, $5 \mu \mathrm{g} / \mathrm{ml}$ of pneumococcal polysaccharide, either $4,6 \mathrm{~B}, 14$ or $23 \mathrm{~F}$, were absorbed onto Nunc Maxisorp microtiter plates (Nunc Roskilde, Denmark) at $37^{\circ} \mathrm{C}$ overnight. Plates were washed with PBS $+0.1 \%$ Tween-20 (PBST). Immunoglobulins were adsorbed with cell wall polysaccharide (CWPS) $(10 \mu \mathrm{g} / \mathrm{ml})$ and PPS22F $(10 \mu \mathrm{g} / \mathrm{ml})$ for 30 minutes at room temperature. After absorption immunoglobulins were serially diluted onto the plates and incubated at $37^{\circ} \mathrm{C}$ for $2 \mathrm{hrs}$; the standard serum 89SF was used as a positive control. Plates were washed and bound antibody was detected using HRP-conjugated anti-human $\operatorname{Ig}(\mathrm{H}+\mathrm{L})$ monoclonal antibody (Southern Biotech) diluted $1 / 3000$ in $1 \%$ BSA PBST and incubated at $37^{\circ} \mathrm{C}$ for $1 \mathrm{hr}$. After washing, plates were developed by using an OPD substrate and the O.D. was read at a wavelength of $490 \mathrm{~nm}$.

\subsection{Disruption ELISA}

Disruption ELISA is a technique used to analyze the general avidity of an antibody to PPS. Briefly, $5 \mu \mathrm{g} / \mathrm{ml}$ of pneumococcal polysaccharide, either 14 or $23 \mathrm{~F}$, were absorbed onto Nunc Maxisorp microtiter plates (Nunc Roskilde, Denmark) at $37^{\circ} \mathrm{C}$ overnight. Plates were washed with PBS $+0.1 \%$ Tween-20 (PBST). Immunoglobulins were mixed with a disrupting agent, sodium thiocyanate $(\mathrm{NaSCN})$, ranging in concentration from $4 \mathrm{M}$ to $0.0625 \mathrm{M}$. Immunoglobulins with $\mathrm{NaSCN}$ were seri- ally diluted onto the plates and incubated at $37^{\circ} \mathrm{C}$ for 2 hours with the standard 89SF serum as a positive control. Plates were washed and bound antibody was detected using HRP-conjugated anti-human $\operatorname{Ig}(\mathrm{H}+\mathrm{L})$ monoclonal antibody (Southern Biotech) diluted $1 / 3000$ in $1 \%$ BSA PBST and incubated at $37^{\circ} \mathrm{C}$ for $1 \mathrm{hr}$. After washing, plates were developed by using an OPD substrate and the O.D. was read at a wavelength of $490 \mathrm{~nm}$.

\subsection{Opsonophagocytic Assay}

To determine functional activity against PPS14 and PPS23F opsonophagocytic assay was performed as previously described [11]. Briefly, S. pneumoniae serotypes 14 and 23F were incubated with serially diluted immunoglobulins. Newborn rabbit serum (Pel-Freez, Brown Deer, WI) was added as a source of complement. Differentiated HL-60 cells were added at an effector/target ratio of 400:1. All immunoglobulins were tested in duplicate. The opsonophagocytic index was determined as the reciprocal of the dilution with $50 \%$ killing when compared to serum free controls and analyzed using the Opsotiter1 software program from the University of Alabama at Birmingham.

\subsection{Purification of PPS-Specific B cells}

Pneumococcal polysaccharide 14 and 23F were fluorescently labeled using Alexa 488 as previously described [12]. Peripheral blood lymphocytes collected day 7 post-vaccination were obtained using Lymphocyte Separation Medium (Mediatech, Inc., Manassas, VA). Cross-reactive B cells were depleted from the population by incubation with beads coated with PPS22F and CWPS and discarded. Isolation of PPS-specific B cells was achieved by incubation with fluorescently labeled PPS14 or PPS23F. Flow cytometric sorting and cloning of single PPS-specific B cells was performed as described previously [13]. PPS-specific B cells were cultured and expanded for 14 days. The supernatants were tested for immunoglobulin secretion and anti-PPS activeity via ELISA. PPS-positive B cell cultures were harvested and lysed for preparation of cDNA.

\subsection{Production of Variable Chain Plasmids}

The cDNA obtained from single PPS-specific B cells was used as a template in PCR for the amplification of the variable chains. Primer sets described previously [14] and Taq polymerase were used to generate variable chain fragments. Heavy and light chain fragments were individually ligated into the TA cloning vector system and transformed into Top 10 Escherichia coli cells. Positive clones were sequenced and re-PCRed to add restriction sites for cloning into the IgG1, pHC-huCg1, or IgG2, 
huCg2, and kappa, pLC-huCk, expression cassettes [15]. The CH1 domain of the antibody is conserved in both $\mathrm{IgG} 1$ and $\mathrm{IgG} 2$ expression cassettes. Correct sequence insertion was confirmed by sequence analysis. The plasmids were a gift from Dr. GR McLean (London, UK).

\subsection{Human Recombinant Immunoglobulin Expression}

The paired $\mathrm{pHC}$ and $\mathrm{pLC}$ plasmids were co-transfected into HEK293 cells using FuGene HD (Roche Basel, Switzerland). After 48 hours, supernatants were tested for immunoglobulin secretion and PPS binding by ELISA as described previously [16].

\subsection{Generation of $F(a b)$ '2 Fragments}

Antibodies were digested using a $\mathrm{F}(\mathrm{ab})$ '2 preparation kit (Pierce, Rockford, IL). Briefly antibodies were desalted and added to spin columns containing resin with immobilized pepsin. The tubes were incubated at $37^{\circ} \mathrm{C}$ for 2 hours while rotating on a end-over-end mixer. Columns were centrifuged and flow-through was collected. Purity of $F(a b) ' 2$ fragments were analyzed by SDS-PAGE.

\subsection{Antibody Avidity Using Surface Plasmon Resonance}

Surface plasmon resonance (SPR) avidity analysis of the recombinant human antibodies was performed using a Reichert SR7000DC instrument with a computer interface for system control and data acquisition (Reichert, Inc., Depew, NY). All experiments were conducted at $25^{\circ} \mathrm{C}$ with a flow rate of $10 \mu \mathrm{l} / \mathrm{min}$ with HBS-EP $(0.01 \mathrm{M}$ HEPES pH 7.4, $0.15 \mathrm{M} \mathrm{NaCl}, 3 \mathrm{mM}$ EDTA, $0.005 \%$ Surfactant P20) as the running buffer. Anti-human IgG or anti-human $\mathrm{F}(\mathrm{ab})$ '2 (SouthernBiotech, Birmingham, $\mathrm{AL}$ ) was diluted to $10 \mathrm{ug} / \mathrm{mL}$ in HBS-EP and covalently immobilized to the surface of the sensor chip using amine coupling chemistry. The recombinant human antibodies or fragments were passed over the chip and captured on the chip's surface. Varying concentrations of PPS14 or PPS23F were then passed over the chip. Avidity measurements for each recombinant antibody were determined by differences in mRIU values. Regeneration was achieved using $3 \mathrm{M} \mathrm{MgCl}_{2}$. Data was analyzed using Scrubber 2 software (Campbell, Australia).

\section{RESULTS}

\subsection{ELISA Studies of IgG1 and IgG2 Expressed VH/VL}

All VH/VL pairs were cloned into both vectors containing human IgG1 Fc and human IgG2 Fc. The ex- pressed immunoglobulins were tested in PPS-specific ELISA. All immunoglobulins were absorbed with CWPS and PPS22F as described in Materials and Methods. The results of these studies demonstrated that all monoclonal antibodies expressed as IgG1 and $\mathrm{IgG} 2$ isotype bound multiple PPSs as shown in Figure 1. Although there were differences in PPS binding between the IgG1 isotype versus IgG2 isotype with identical $\mathrm{VH} / \mathrm{VL}$ as measured by ELISA, these differences were not significant.

\subsection{Disruption ELISA}

Binding to PPS was disrupted by adding different dilutions of NaSCN to the ELISA well. Overall avidity was measured by the concentration of $\mathrm{NaSCN}$ required to disrupt $50 \%$ of binding measured at $0 \mathrm{M} \mathrm{NaSCN}$. These studies demonstrated relatively weak binding to both PPS14 and PPS23F. On average, $0.083 \mathrm{M} \mathrm{NaSCN}$ was needed to disrupt monoclonal binding to both PPS14 and PPS23F (Table 1). In many cases, a higher concentration of $\mathrm{NaSCN}$ was needed to disrupt the $\mathrm{IgG} 1$ isotype binding compared to the IgG2 isotype although the difference was not significant.

\subsection{Opsonophagocytic Studies}

To ascertain the functional activity of the expressed immunoglobulins, an opsonophagocytic assay was performed. As shown in Figure 2, monoclonal antibodies expressed as IgG1 had a high opsonophagocytic index (OI) against PPS14. Moreover, all monoclonal antibodies expressed as IgG2 also killed type 14 pneumococcus, however the OI was considerably lower than for the IgG1 antibodies despite identical VH/VL. Similarly, all IgG1 monoclonal antibodies also killed S. pneumonia serotype $23 \mathrm{~F}$ with greater opsonophagocytic index than their VH/VL identical IgG2 counterparts.

\subsection{Variable Region Analysis}

We performed sequence analysis of VL and VH regions of all monoclonal antibodies as shown in Table 2. The eight VL regions belonged to a total of 5 different

Table 1. Disruption ELISA. Monoclonal antibodies were incubated with varying concentrations of NaSCN. Avidity index equals the molar $(\mathrm{M})$ concentration of $\mathrm{NaSCN}$ needed to disrupt monoclonal binding to PPS by $50 \%$.

\begin{tabular}{ccccc}
\hline \multirow{2}{*}{$\begin{array}{c}\text { Avidity } \\
\text { Index (M) }\end{array}$} & \multicolumn{3}{c}{ PPS14 } & PPS23F \\
\cline { 2 - 5 } & $\operatorname{IgG1}$ & $\operatorname{IgG} 2$ & $\operatorname{IgG} 1$ & $\operatorname{IgG} 2$ \\
\hline $32 \mathrm{E} 8$ & 0.027 & 0.025 & 0.093 & 00935 \\
$31 \mathrm{~B} 5$ & 0.11 & 0.076 & 0.14 & 0.089 \\
$33 \mathrm{E} 2$ & 0.151 & 0.0455 & 0.0454 & 0.0453 \\
\hline
\end{tabular}




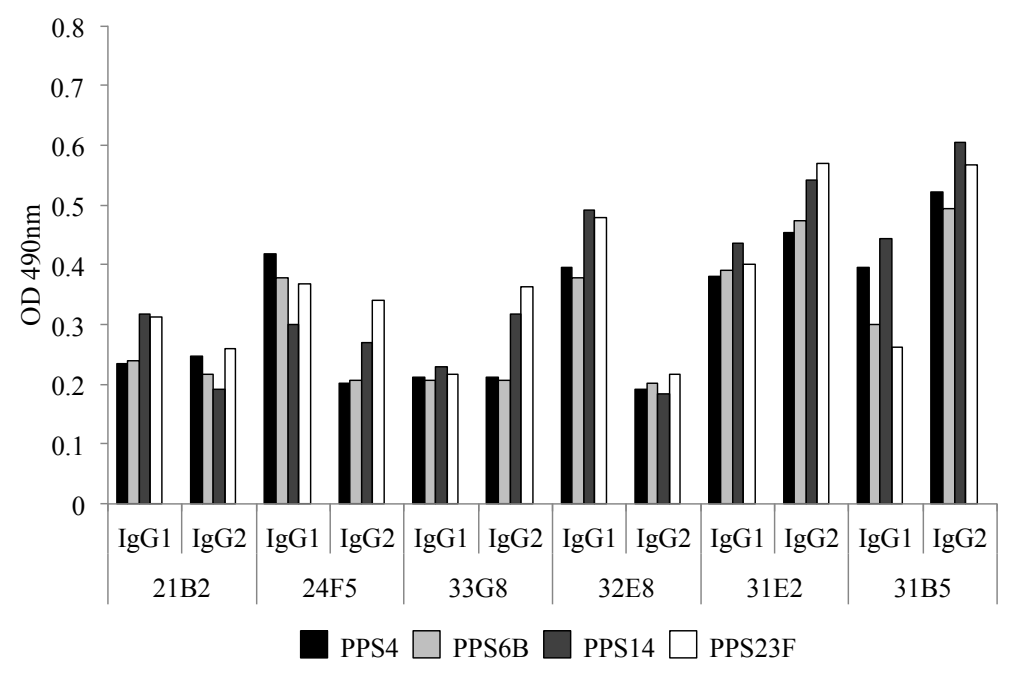

Figure 1. Monoclonal antibodies, 21B2, 24F5, 33G8, 32E8, 31E2 and 31B5, bound multiple pneumococcal polysaccharides after absorption with PPS22F and CWPS as assessed by ELISA.



Figure 2. Opsonophagocytic assay of clones against serotype 14 and $23 \mathrm{~F}$ pneumococcus. Bactericidal ability is associated with functional activity.

VL gene families, namely A20, O12, L5, A27 and B3.

The predominant $\mathrm{VL}$ gene families represented were A20 and O12. The CDR3 region, thought to be crucial in antigen binding, of all monoclonal antibodies (MAbs) with the exception of 33E2, expressed a kappa VL gene with a CDR3 length of 9 amino acids (AA) (Figure 3(a)). In addition there was an absence of overall negatively charged AA in the Vk CDR3 region (Figure 3(b)). The number of mutations in the VL varied greatly between monoclonal antibodies from 10 mutations in MAb 33G8 to 37 in the heavily mutated

$\mathrm{MAb} 21 \mathrm{~B} 2$. Monoclonal antibodies 21B2 and 32E8 displayed identical VL however they were paired with different $\mathrm{VH}$.

Analysis of the $\mathrm{VH}$ regions demonstrated that 7 of the
$8 \mathrm{VH}$ region expressed gene products belonged to the VH3 gene family. The VH3-23 gene family was predominantly expressed although none of the VH3-23 sequences were identical. In contrast to the VL CDR3s, the $\mathrm{VH}$ chains of these antibodies showed varying CDR3 lengths ranging from $12 \mathrm{AA}$ in $\mathrm{MAb} 33 \mathrm{E} 2$ to $24 \mathrm{AA}$ in $\mathrm{MAb} 24 \mathrm{~F} 5$. The number of charged molecules in the VH CDR3s ranged from a total of 3 to 6 positively and/or negatively charged amino acids per CDR3 (Figure 3(c)). Amino acids arginine, tryptophan and tyrosine have been reported to be responsible for increasing the plasticity of the antigen binding region, allowing the antibody to recognize multiple antigens [17]. All VH CDR3 regions possessed varying numbers of these three amino acids ranging from 2 to 9 . Monoclonal antibody $33 \mathrm{G} 8$ has the 

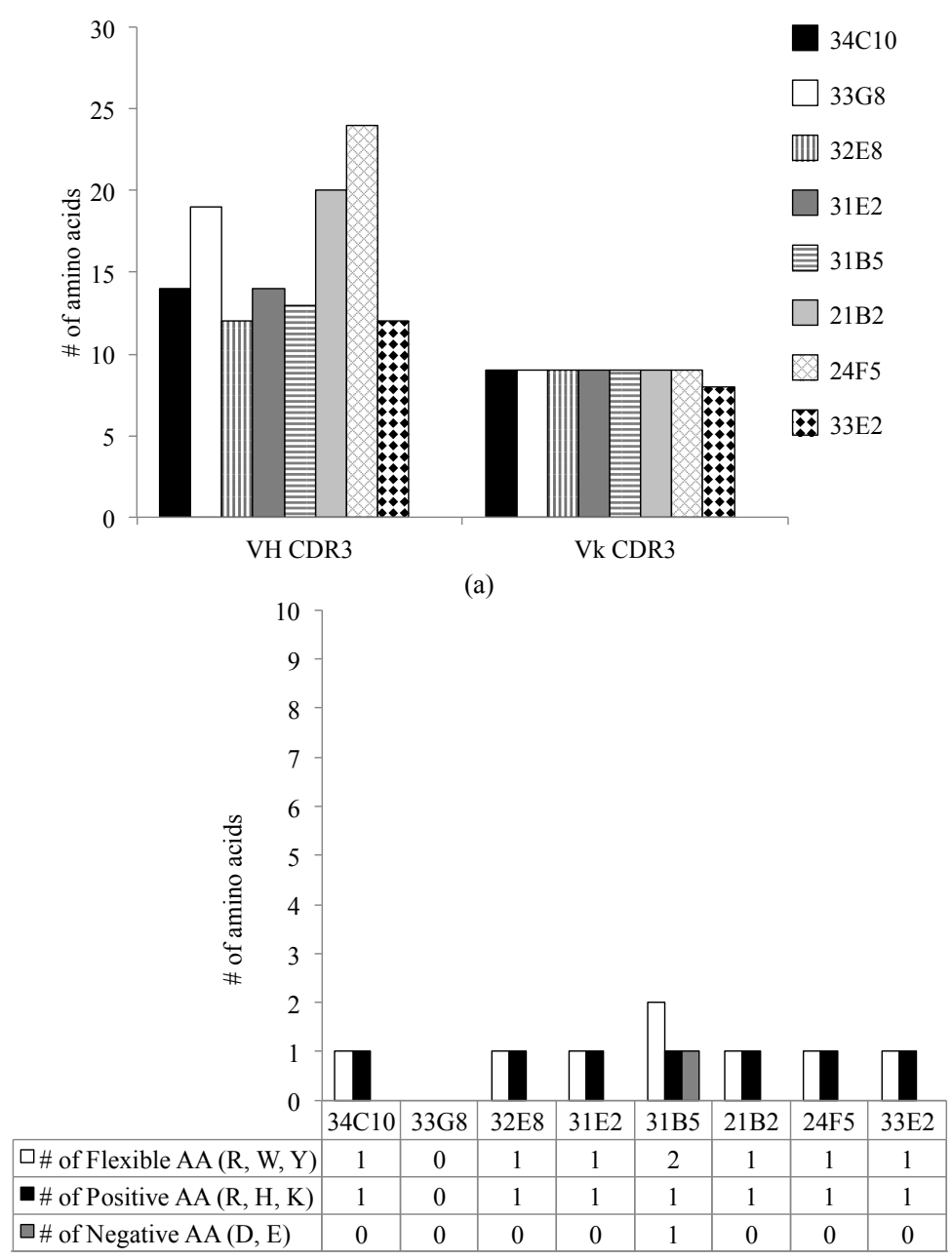

(b)

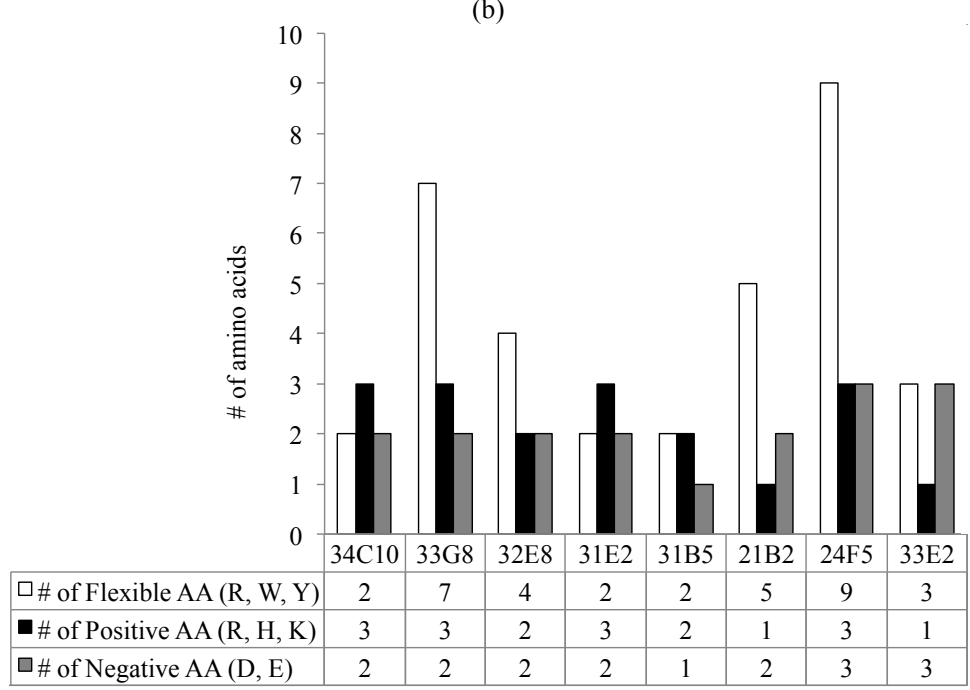

(c)

Figure 3. (a) The length of the CDR3 in number of amino acids. While the VH chain CDR3s exhibit varying length, the VL chain CDR3s share the same number of amino acids, 9, with the exception of 33E2 which has 8 amino acids. Another shared characteristic of these nonspecific clones is the absence of negative amino acids in their Vk CDR3 (b) and an increase in the number of flexible amino acids in the VH CDR3 (c). 
Table 2. Sequence analysis of polyreactive clones isolated from single B cell culture. Shown are VH (top table) and VL (bottom table) CDR3 sequence, number of mutations, homology to germline, V and J gene usage.

\begin{tabular}{|c|c|c|c|c|c|c|}
\hline Clone & \multicolumn{2}{|r|}{ VH CDR3 } & \# of Mutations & $\%$ Homology & V gene & J gene \\
\hline $34 \mathrm{C} 10$ & & SRGSTPRAFDP & 12 & 97 & $3-23$ & $\mathrm{JH} 5 \mathrm{~b}$ \\
\hline $33 \mathrm{G} 8$ & & QWLVRPYYYGMDV & 5 & 99 & $1-18$ & JH6b \\
\hline $32 \mathrm{E} 8$ & & NRWQQSEFDY & 29 & 93 & $3-07$ & $\mathrm{JH} 4 \mathrm{~b}$ \\
\hline $31 \mathrm{E} 2$ & & SRGSTPRAFDP & 36 & 88 & $3-66$ & $\mathrm{JH} 5 \mathrm{~b}$ \\
\hline 31B5 & & KAFSGYSPFDY & 20 & 94 & $3-23$ & $\mathrm{JH} 4 \mathrm{~b}$ \\
\hline 21B2 & & GATDPPYYYYGMDV & 5 & 99 & $3-30$ & JH6b \\
\hline $24 \mathrm{~F} 5$ & & SSSWYYPFYYYGMDV & 4 & 99 & $3-23$ & JH6b \\
\hline $33 \mathrm{E} 2$ & & EEYYGSGFDP & 4 & 99 & $3-48$ & $\mathrm{JH} 5 \mathrm{~b}$ \\
\hline & Clone & Vk CDR3 & \# of Mutations & \% Homology & & $V$ gene \\
\hline & $34 \mathrm{C} 10$ & QKYNSAPFT & 12 & 99 & & $\mathrm{~A} 20$ \\
\hline & $33 \mathrm{G} 8$ & QQANSFSLT & 10 & 99 & & L5 \\
\hline & $32 \mathrm{E} 8$ & QRSSGGPIS & 35 & 90 & & $\mathrm{O} 12$ \\
\hline & $31 \mathrm{E} 2$ & QKYNGAPFT & 14 & 97 & & $\mathrm{~A} 20$ \\
\hline & 31B5 & QQYDRSPLT & 15 & 98 & & A27 \\
\hline & 21B2 & QRSSGGPIS & 37 & 89 & & $\mathrm{O} 12$ \\
\hline & $24 \mathrm{~F} 5$ & QKYNGAPFT & 15 & 93 & & $\mathrm{~A} 20$ \\
\hline & $33 \mathrm{E} 2$ & QQHYNTPT & 14 & 98 & & B3 \\
\hline
\end{tabular}

highest number of arginine residues in the VH CDR3. Monoclonal antibody 24F5 has the highest number of tryptophan residues. The number of mutations in the VH CDR3 varied greatly from 4 mutations in MAb 24F5 and 33E2 to 36 mutations in MAb 31E2. The $\mathrm{VH}$ regions with longer CDR3 regions had a tendency towards lower number of mutations (Table 2).

There was no correlation between the length of the CDR3 of the VL and the VH regions. Thus, MAbs with varying VH CDR3 lengths ranging from 12 to 24 amino acids were all paired with a VL with a CDR3 length of 9 amino acids. Some heavily mutated VL regions, for example VL 21B2 and VL 24F5 were paired with minimally mutated $\mathrm{VH}$ regions that closely resembled germline sequence. Monoclonal antibody 32E8 was the only clone that expressed a heavily mutated VH and VL.

The monoclonals analyzed in this study were compared to previously published polyreactive and PPSspecific antibodies [18-23]. Variable heavy and light CDR3 percent homology to germline sequences were not significantly different between PPS-specific and polyreactive populations (Figure 4(a)). In contrast, the average CDR3 length was notably longer in polyreactive $\mathrm{VH}$ CDR3 compared to PPS-specific antibodies (Figure 4(b)).
Overall, the polyreactive antibodies possessed a significantly higher number of flexible amino acids in the $\mathrm{VH}$ CDR3 than the PPS-specific VH CDR3 (Figure 4(c)). There was no significant difference in the number of flexible amino acids in the VL CDR3 between the polyreactive and PPS-specific antibodies (Figure 4(d)).

\subsection{Avidity Analysis of IgG Antibodies}

In addition to the disruption avidity ELISA studies, both MAb IgG1 and IgG2 clones were tested for antibody avidity using SPR. A chip was coated with antihuman IgG by amine coupling. Cell culture supernatant containing monoclonal antibody preparation was passed over the chip, capturing the monoclonal antibody

This method allows for uniform binding of the recombinant antibody to the chip. Varying concentrations of PPS14 or PPS23F were passed over the surface of the chip and antigen-antibody binding was measured by SPR. As expected, these polyreactive antibodies exhibited low avidity for pneumococcal polysaccharide (Figure 5). Binding rates were detectable in the micromolar range, from 5.3 to 0.12 , for all clones. In contrast, a mouse monoclonal antibody specific for PPS14 was calculated to have an avidity of $70 \mathrm{nM}$ which is significantly 


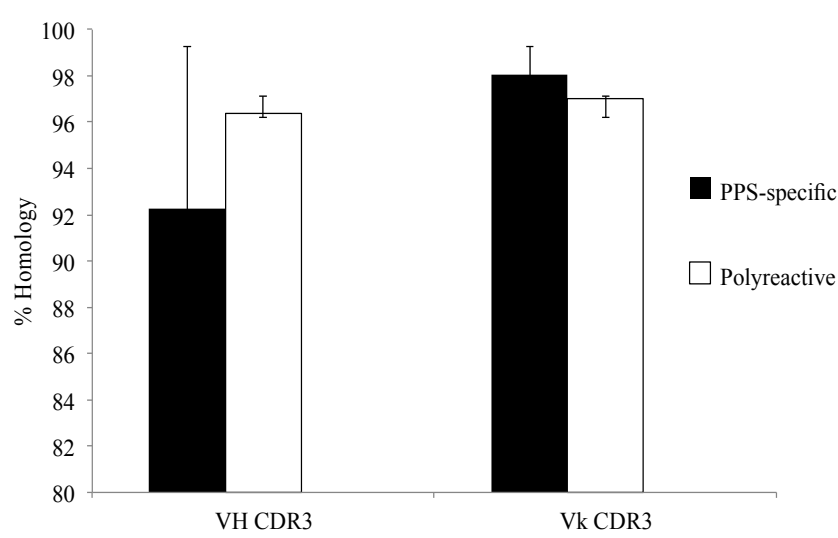

(a)

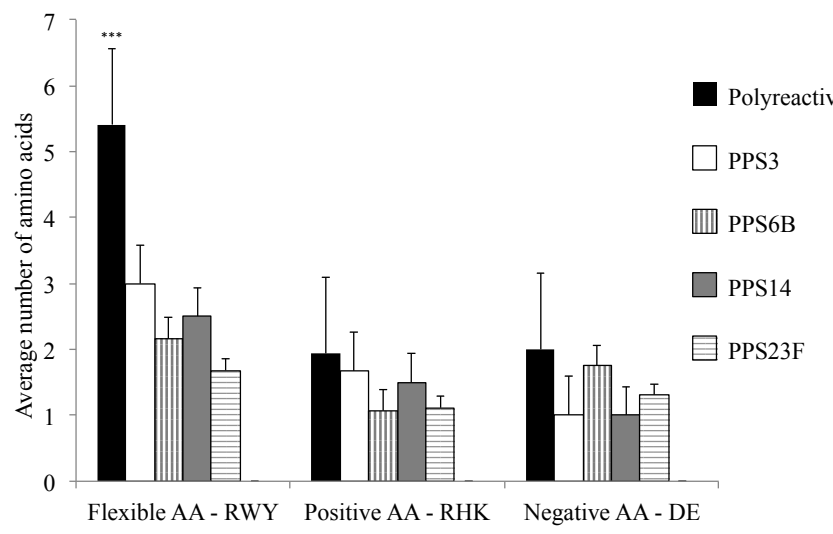

(c)

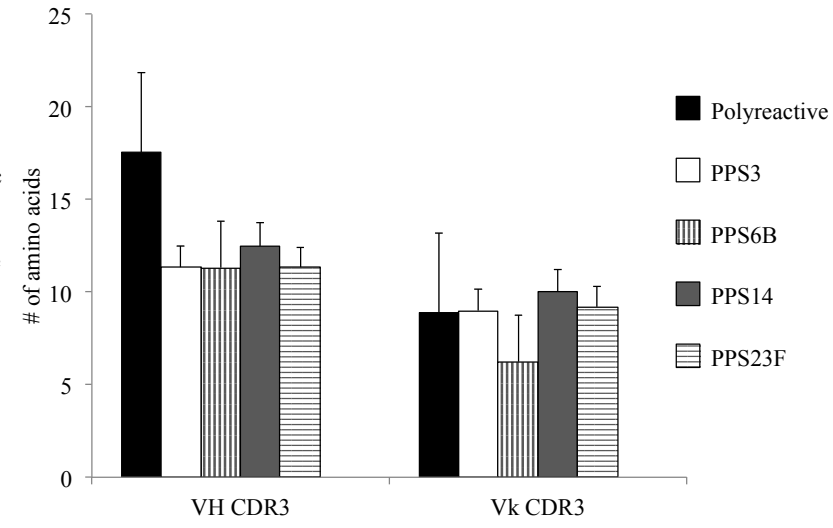

(b)



(d)

Figure 4. (a) Analysis of homology of the CDR3 to germline. There was no significant difference in germline homology between PPS-specific and polyreactive CDR3. (b) The average VH CDR3 length was notably longer for polyreactive antibodies when compared to the PPS-specific sequences. Comprehensive VH (c) and Vk (d) CDR3 amino analysis of published anti-pneumococcal polysaccharide antibodies. Amino acid abbreviations: Arginine-R, tryptophan-W, tyrosine-Y, histidine-H, lysine-K, aspartic acid-D and glutamic acid-E. Number of sequences analyzed for each serotype in parentheses. Difference between RWY VH composition is statistically significant ${ }^{* * *} \mathrm{p}<0.0001$.

stronger than the polyreactive antibodies analyzed.

As shown in Figure 5(a), all MAbs expressed as IgG1 molecules, with the exception of MAb 33G8, bound PPS14 more avidly than their homologous MAb expressed as IgG2. There was a notable difference in antibody avidity between IgG1 and IgG2 forms of the same $\mathrm{VH} / \mathrm{VL}$ pair in all cases. A similar trend was detected in MAb binding to PPS23F. Most Mabs expressed in the IgG1 form bound more avidly than their IgG2 counterpart with the exception of Mabs 33G8 and 32E8. Differences in binding between the IgG1 and IgG2 isoforms were observed for only 3 of the 5 MAbs tested, namely 21B2, 24F5 and 33G8. There was no correlation between the antibody avidity and length of the VH CDR3 or between avidity and number of mutations in either $\mathrm{VH}$ or VL or combined VH/VL. Overall for both polysaccharides the IgG1 isoform bound more avidly than it's IgG2 counterpart although these differences were not statistically significant.

\subsection{Avidity Analysis of $F(a b)$ '2 Fragments}

Recombinant antibodies were digested with pepsin to produce $F(a b)$ '2 2 fragments. $F(a b) ' 2$ fragment purity was analyzed using SDS-PAGE as demonstrated in Figure 6. Pepsin digestion removes the $\mathrm{CH} 2$ and $\mathrm{CH} 3$ domains keeping the hinge region intact. Surface plasmon resonance analysis of the pepsin digested fragments resulted in the elimination of the differences in binding kinetics observed between the IgG1 and IgG2 isotypes as shown in Table 3. The binding constants for these fragments were significantly lower than the values of their undigested IgG1 and IgG2 forms.

\section{DISCUSSION}

Natural antibodies are able to recognize and bind a variety of foreign and self-antigens including protein and polysaccharide antigens. Natural antibodies have been reported for several bacterial polysaccharides however 

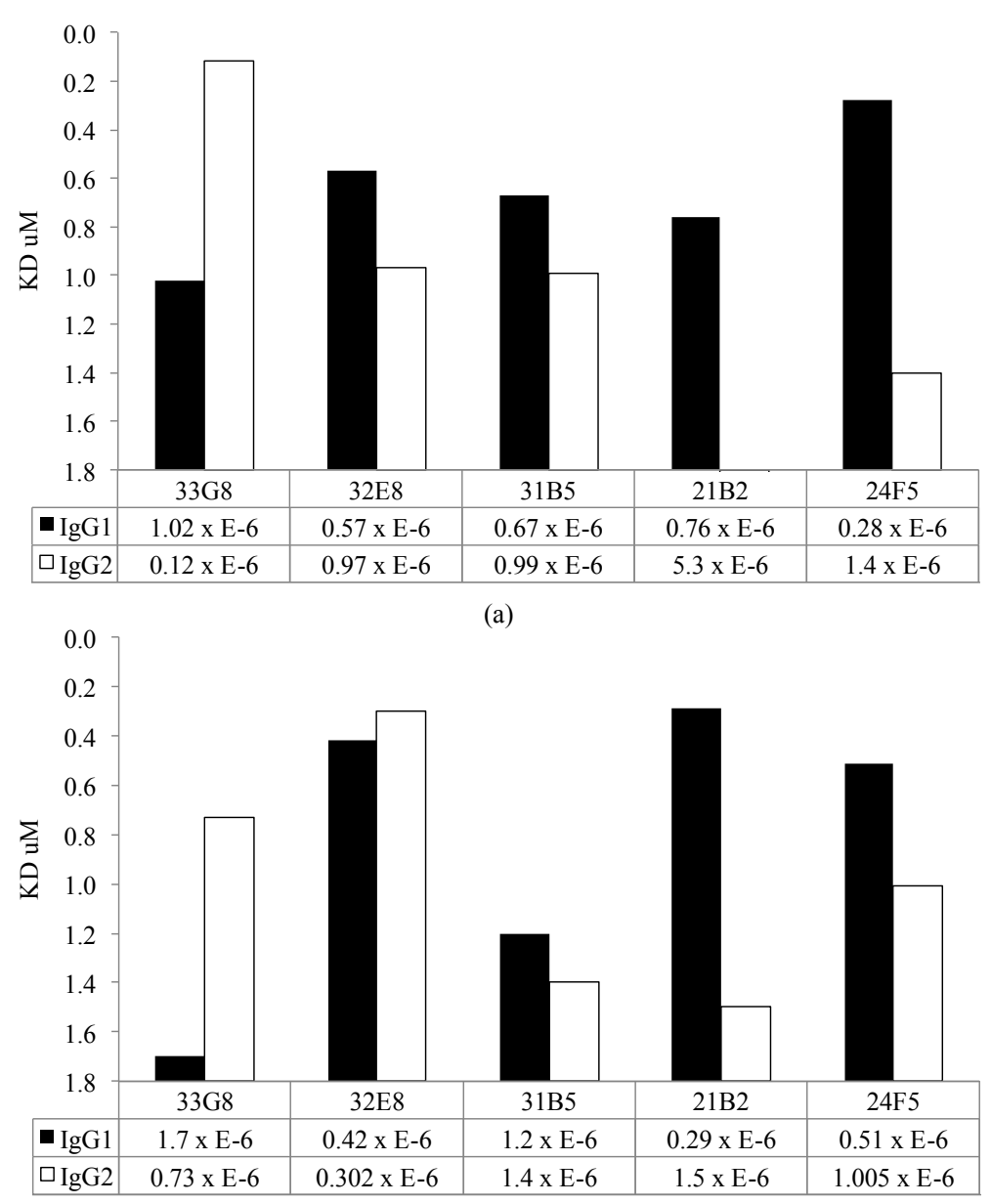

(b)

Figure 5. Kinetic analysis of MAbs avidity to PPS14 (a) and PPS23F (b) using $\mathrm{SPR}$. Antigen binding is expressed as $\mathrm{Kd} \cdot \mathrm{mol}^{-1}$.

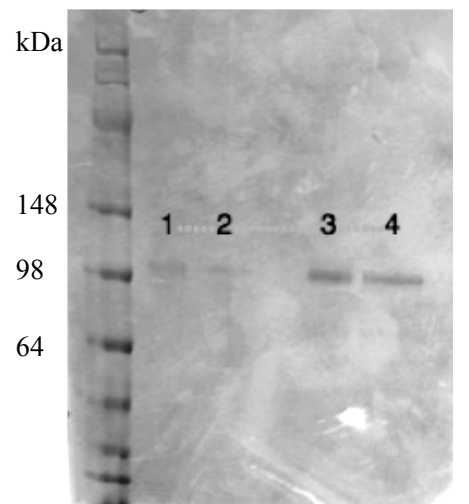

Figure 6. Analysis of antibody digestion with pepsin to produce $\mathrm{F}(\mathrm{ab})$ '2 2 fragments. All digested clones (clone 24F5 shown here) resulted in complete $\mathrm{F}(\mathrm{ab})$ ' 2 digestion before and recovery after protein $\mathrm{A}$ column. Lane: 1. 24F5 IgG1 F(ab)'2 digested, 2. 24F5 IgG1 F(ab)'2 digested + protein A column, 3. 24F5 IgG2 F(ab)'2 digested, 4. 24F5 IgG2 F(ab)'2 digested + protein A column.
Table 3. Kinetic analysis of F(ab)'2 fragment avidity to PPS14 and PPS23F. Recombinant antibodies were digested with pep$\sin$.

\begin{tabular}{ccccc}
\hline $\mathrm{K}_{\mathrm{D}}$ & \multicolumn{2}{c}{ PPS14 } & \multicolumn{2}{c}{ PPS23F } \\
\hline Clone & IgG1 F(ab)'2 & IgG2 F(ab)'2 & IgG1 F(ab)’2 & IgG2 F(ab)'2 \\
$33 \mathrm{G} 8$ & $0.49492 \mathrm{uM}$ & $0.5001 \mathrm{uM}$ & $0.500 \mathrm{uM}$ & $0.4989 \mathrm{uM}$ \\
21B2 & $0.5359 \mathrm{uM}$ & $1.35362 \mathrm{uM}$ & $0.69445 \mathrm{uM}$ & $0.80091 \mathrm{uM}$ \\
24F5 & $1.07 \mathrm{uM}$ & $1.16921 \mathrm{uM}$ & $0.98 \mathrm{uM}$ & $1.00 \mathrm{uM}$ \\
\hline
\end{tabular}

the characteristics of these antibodies remain to be elucidated. Low avidity polyreactive antibodies are believed to be the body's first line of defense against pathogens and can initiate complement deposition. Polyreactive antibodies, referred to as "natural antibodies", include $\operatorname{IgM}, \mathrm{IgG}$ and $\operatorname{IgA}$ isotypes [24], mainly use $\mathrm{VH} 3, \mathrm{VH} 4$ or VH5 genes and classically contain few mutations, i.e. resemble germline sequences [25]. It is generally accepted that highly mutated Abs are derived from conventional antibody producing cells, referred to as B2 cells, 
and generated through antigen-driven somatic hypermutation. Another subset of B cells, B1 cells, may play a significant role in the innate immunity to encapsulated organisms. In mice, these cells are phenoltypically defined by CD5 expression. Compared to conventional B2 cells, they are unique in several aspects including phenotype and production of natural Abs [26,27]. The antibodies produced by B1 cells bind autoantigens and are broadly cross-reactive to a variety of bacterial antigens i.e. PPS and LPS [28]. Murine studies demonstrate that these $\mathrm{CD}^{+} \mathrm{IgM}^{+} \mathrm{B}$ cells spontaneously secrete natural antibodies that appear to play a crucial role as the first line of defense against bacterial and viral pathogens including the pneumococcus [29-32]. Thus $\mathrm{CD}^{+} \mathrm{B}$ cells, in particular the $\mathrm{CD}^{+} \mathrm{B} 1$ cells, are thought to be responsible for the production of natural antibodies in humans.

In effort to better characterize human polyreactive pneumococcal immunoglobulins, we initially tested the specificity of our MAbs using a PPS ELISA. The standard WHO protocol was used to detect PPS-binding immunoglobulin from B cells in culture. Even with the use of CWPS and PPS22F during the absorption step, the monoclonal antibodies studied here bound multiple pneumococcal polysaccharides and therefore were considered polyreactive antibodies. Despite low antibody avidity, all polyreactive antibodies tested had high opsonophagocytic activity and induced opsonization of both serotypes, PPS14 and PPS23F (Figure 2) suggesting they are not only polyreactive but are indeed functional. Antibodies with a high opsonophagocytic activity and low avidity have previously been reported by Baxendale et al. and Romero-Steiner et al. [33,34]. This observation is in sharp contrast to studies that have shown that reduced or absent functional antibody activity, as determined by opsonophagocytic or mouse protection assays, is directly related to low antibody avidity $[35,36]$. Although some studies directly correlate antibody avidity with functional activity, this appears not to be true for all antigen-specific antibodies. Several factors are likely to influence antibody avidity. These include factors that affect intrinsic affinity, such as VH/VL molecular structure, but also by other factors, potentially constant region structure, that may affect the number of binding sites and antibody flexibility [37]. The criterion governing antibody avidity and functional activity of both antigen-specific and polyreactive antibodies however, remains to be elucidated.

Monoclonal antibody avidity was tested by both disruption ELISA and directly by surface plasmon resonance. While these antibodies bound multiple polysaccharides in ELISA studies, their binding was relatively weak as demonstrated by the low concentrations of NaSCN required to disrupt binding to PPS. The avidity constant, as measured by SPR corresponded directly to the NaSCN ELISA studies and demonstrated weak antigen binding. The results of these studies are in accordance with previous findings concerning antibody avidity of natural antibodies $[11,26]$.

Antibody avidity for pneumococcal polysaccharides is determined not only by the sequence of the variable region but also by the way the variable region interacts with the surface of the polysaccharide. The pneumococcal polysaccharide antigen consists of repeating saccharide units. Anti-PPS antibody variable regions are directed against two different molecular patterns. They recognize either one or two monosaccharides at the terminal ends of the polysaccharide or alternatively, recognize extended sugar epitopes of 6 or 7 monosaccharides [38]. Moreover, structural constraints of the PPS epitopes may limit the interaction with the antibody variable region [22]. It has been postulated that a uniformed CDR3 length may allow for the binding of similarly spaced epitopes. The polyreactive monoclonals analyzed have VL CDR3s of similar length. Preserved VL CDR3 length has been reported with other polyreactive antibodies [39, 40]. In contrast, the length of the VL chain CDR3 in PPS-specific antibodies has been reported to be variable ranging from 4 to 11 amino acids [20,22,41]. Variable light CDR3 length reportedly influences the loop configuration of the antibody/antigen-binding site. In fact, Wang et al. has suggested that a change in length of the VL CDR3 may have a more significant effect than amino acid substitutions [42]. These findings suggest that the homogeneous VL CDR3 length may be a feature of polyreactive antibodies while PPS-specific antibodies do not have this restriction. Alternatively, this range of VL CDR3 length in PPS-specific antibodies may be related to the restricted use of the A23 and L6 gene families, at least in the case of PPS23F-specific antibodies [20]. These gene families were absent in our eight polyreactive PPS23F-binding monoclonal antibodies. Moreover, the polyreactive VL CDR3s lacked positive or negatively charged amino acids. Charged amino acids in the CDR3 may result in repulsion of the antigen preventing antibody binding. However, it should be mentioned that some PPS-specific VL CDR3s also lack highly charged amino acids.

In contrast to the uniform VL CDR3 length, the VH CDR3 varied greatly in length ranging from 12 to 24 amino acids. Similarly, the VH CDR3 of PPS-specific antibodies is reported to vary greatly from 4 to 20 amino acids, although the median VH CDR3 length of polyreactive antibodies is notably longer, some overlap is evident [18-23]. Thus the overall longer length of the $\mathrm{VH}$ CDR3 is more commonly observed with polyreactivity. Moreover, germline sequences tend to possess a longer CDR3 than heavily mutated Abs. The longer CDR3 of these polyreactive antibodies may facilitate binding to 
larger epitopes $[43,44]$.

The amino acid arginine has been associated with antibody polyreactivity [45]. Polyreactivity may be the result of electrostatic interactions mediated by arginine in the VH chain CDR3. Among our polyreactive clones, all but one possess at least one arginine in the VH CDR3. Other amino acids which contribute to polyreactivity are tryptophan and tyrosine. These residues interact with a diverse array of antigens due to their ability to form hydrogen bonds, hydrophobic interactions, electrostatic interactions and aromatic rings [45]. Amino acids with flexible side rings may also make the binding region more plastic allowing for interaction with different antigens. Monoclonals 21B2 and 32E8 both possess the same VL chain. However, 21B2 VH chain exhibits more of the flexible amino acids and bound both PPS14 and PPS23F more avidly than 32E8 in SPR studies. Pneumococcal polysaccharide-specific antibodies tend to express fewer flexible amino acids, on average 3.6 amino acids in combined VL/VH CDR3s, in contrast to our polyreactive clones which contained 6.4 flexible molecules. This lack of flexible amino acids theoretically decreases antibody elasticity and may therefore result in a more rigid and specific antibody molecule [20].

Natural antibody variable regions classically possess few mutations and are closely related to germ-line. Among the clones analyzed in our study the number of variable region mutations varied greatly. The number of VL mutations varied from 10 to 37 while the number of VH mutations varied from 4 to 36 . Monoclonals 33E2, 21B2, 24F5 and 33G8 conform to the classic idea of natural antibodies with few mutations in their VH. There was no association between the number of VL mutations and the number of $\mathrm{VH}$ mutations found in these clones. Similarly, there was no correlation between the number of mutations and the CDR3 length. In summary, some of our polyreactive antibodies conformed to the classic image of polyreactive antibodies while others were highly mutated in either the VH or VL or both. Casali et al. demonstrated that B1 cells could generate hypermutated antibodies. Moreover, using a variety of techniques including gene shuffling and site-directed mutagenesis, they showed that the immunoglobulin VH region provides the major structural predictor for antibody polyreactivity, mainly provided by the heavy chain CDR3 [44]. The ability of B1 cells to generate hypermutated antibodies may explain the high number of mutations in clones 32E8, 31E2 and 31B5.

The polyreactive antibodies we analyzed were expressed in IgG1 and IgG2 form. It has been reported that antibody isotype, thus antibody constant region, may influence antibody fine specificity and avidity. Schreiber et al. expressed a VL/VH pair with specificity for Haemophilus influenzae type $\mathrm{b}$ as various isotypes. These investigators noted that different isotypes with identical $\mathrm{VL} / \mathrm{VH}$ resulted in variable protective immunity likely attributable to variable binding avidity [46]. Similarly, Baxendale et al. found differences in antibody avidity to PPS between IgA1 and IgG2 clones with identical $\mathrm{VL} / \mathrm{VH}$, suggesting the $\mathrm{Fc}$ region may influence antigen binding [33]. Torres et al. analyzed IgG murine antibodies with identical variable regions demonstrated diverse binding affinity and fine specificity suggesting the constant region affects the variable region binding to Crytptococcus neoformans [47]. This discrepancy in antigen binding despite identical variable regions has also been documented for protein antigens [48]. Consistent with previous reports, we also found a significant difference in binding avidity between $\operatorname{IgG} 1$ and $\mathrm{IgG} 2$ isotypes with identical $\mathrm{VH} / \mathrm{VL}$ regions. The IgG1 isoform of most of our polyreactive monoclonal antibodies demonstrated a greater avidity and bactericidal activity than IgG2 isoforms expressing identical VL/VH pairs. Morelock et al. attributes this increased avidity of IgG1 isotype to unimpeded Fab arm movement and increased hinge flexibility. Thus the constant region appears to affect the conformation of the variable region [49]. Moreover, changes in conformation imposed by the constant region may allow for different antibody isotypes with identical variable regions to recognize different epitopes. However when these antibodies were digested to $F(a b)$ ' 2 fragments these differences were abolished. This phenomenon was previously reported with a protein antigen [50]. This suggests the $\mathrm{CH} 2$ and $\mathrm{CH} 3$ regions of the constant region act as a supportive structure to maintain the conformation of the antibody and result in significant differences in binding avidity between isotypes [51]. Loss of the $\mathrm{CH} 2$ and $\mathrm{CH} 3$ removes supportive scaffolding causing loss of a structured hinge which may explain the differences in avidity between IgG1, IgG2 and F(ab)'2 fragments. Additionally, there is evidence that polyreactivity may be influenced by the surrounding constant region structures. Thus, structures that make the antigen binding site more flexible, may allow the antibody to bind multiple antigens [47]. The IgG1 isoform possesses fewer disulfide bonds and more amino acids in the constant region resulting in greater flexibility. This increase in molecular flexibility may, in part, explain the overall increased avidity of the IgG1 isotype for these polyreactive monoclonal antibodies. Although the variable region is responsible for antigen recognition, the constant region of the antibody is necessary for stability, fine specificity and optimal avidity.

Polyreactive antibodies to PPS in our study despite low avidity by disruption ELISA and SPR were bactericidal against multiple serotypes of pneumococcus suggesting clinical significance. The $\mathrm{VH}$ regions expressed were mainly VH3, namely VH $3-23$. Although VL con- 
served CDR3 length, VH CDR3 length varied greatly as did the number of mutations. Moreover, the VH CDR3 was characteristically longer than PPS-specific antibodyies. Additionally the CDR3 possessed more arginine, tyrosine and tryptophan amino acids allowing for a greater flexibility compared to PPS-specific antibodies. Each VH/VL pair was expressed as IgG1 and IgG2 isotypes. Overall for both PPS14 and PPS23F, the IgG1 isotype bound more avidity to PPS and was more functional corresponding to higher avidity suggesting a role of the constant region in antibody specificity and function. The common characteristics discovered in these human polyreactive antibodies may aid in establishing guidelines for the detection of the natural human antipneumococcal antibody in the repertoire.

\section{ACKNOWLEDGEMENTS}

This work was supported by National Institutes of Health grants RO1A081558 and RO1AG015978 to M.A.J.W.

\section{REFERENCES}

[1] (1997) Prevention of pneumococcal disease: Recommendations of the Advisory Committee on Immunization Practices (ACIP). Morbidity and Mortality Weekly Report, 46, 1-24. http://www.ncbi.nlm.nih.gov/pubmed/9132580

[2] Whitney, C.G., Farley, M.M., Hadler, J., Harrison, L.H., Bennett, N.M., Lynfield, R., Reingold, A., Cieslak, P.R., Pilishvili, T., Jackson, D., Facklam, R. R., Jorgensen, J.H. and Schuchat, A. (2003) Decline in invasive pneumococcal disease after the introduction of proteinpolysaccharide conjugate vaccine. New England Journal of Medicine, 348, 1737-1746. doi:10.1056/NEJMoa022823

[3] Avery, O.T.A.W.F.G. (1929) Chemo-immunological studies on conjugated carbohydrate proteins. II. Immunological specificity of synthetic sugar-protein antigens. Journal of Experimental Medicine, 50, 533-550. doi:10.1084/jem.50.4.533

[4] Alugupalli, K.R. and Gerstein, R.M. (2005) Divide and conquer: Division of labor by B-1 B cells. Immunity, 23, 1-2. doi:10.1016/j.immuni.2005.07.001

[5] Chen, X., Martin, F., Forbush, K.A., Perlmutter, R.M. and Kearney, J.F. (1997) Evidence for selection of a population of multi-reactive B cells into the splenic marginal zone. International Immunology, 9, 27-41. doi:10.1093/intimm/9.1.27

[6] Martin, F. and Kearney, J.F. (2000) Positive selection from newly formed to marginal zone B cells depends on the rate of clonal production, CD19, and btk. Immunity, 12, 39-49. doi:10.1016/S1074-7613(00)80157-0

[7] Julien, S., Soulas, P., Garaud, J.C., Martin, T. and Pasquali, J.L. (2002) B cell positive selection by soluble self-antigen. Journal of Immunology, 169, 4198-4204.

[8] Widhopf, G.F., Brinson, D.C., Kipps, T.J. and Tighe, H. (2004) Transgenic expression of a human polyreactive Ig expressed in chronic lymphocytic leukemia generates memory-type B cells that respond to nonspecific immune activation. Journal of Immunology, 172, 2092-2099.

[9] Griffin, D.O., Holodick, N.E. and Rothstein, T.L. (2011) Human B1 cells in umbilical cord and adult peripheral blood express the novel phenotype CD20+ CD27+ CD43+ CD70. Journal of Experimental Medicine, 208, 67-80. doi:10.1084/jem.20101499

[10] Nahm, M.G.D. (2002) Training manual for enzyme linked immunosorbent assay for the quantitation of Streptococcus pneumoniae serotype specific IgG ( $\mathrm{PnPg}$ ELISA). Accessed on 18 April 2011.

http://www.vaccine.uab.edu

[11] Romero-Steiner, S., Libutti, D., Pais, L.B., Dykes, J., Anderson, P., Whitin, J.C., Keyserling, H.L. and Carlone, G.M. (1997) Standardization of an opsonophagocytic assay for the measurement of functional antibody activity against Streptococcus pneumoniae using differentiated HL-60 cells. Clinical and Diagnostic Laboratory Immunology, 4, 415-422.

[12] Shafer, D.E., Toll, B., Schuman, R.F., Nelson, B.L., Mond, J.J. and Lees, A. (2000) Activation of soluble polysaccharides with 1-cyano-4-dimethylaminopyridinium tetrafluoroborate (CDAP) for use in proteinpolysaccha- ride conjugate vaccines and immunological reagents. II. Selective crosslinking of proteins to CDAP-activated polysaccharides. Vaccine, 18, 1273-1281. doi:10.1016/S0264-410X(99)00370-9

[13] Weitkamp, J.H., Kallewaard, N., Kusuhara, K., Feigelstock, D., Feng, N., Greenberg, H.B. and Crowe, J.E. Jr. (2003) Generation of recombinant human mono-clonal antibodies to rotavirus from single antigen-specific $B$ cells selected with fluorescent virus-like particles. Journal of Immunological Methods, 275, 223-237. doi:10.1016/S0022-1759(03)00013-9

[14] Welschof, M., Terness, P., Kolbinger, F., Zewe, M., Dubel, S., Dorsam, H., Hain, C., Finger, M., Jung, M., Moldenhauer, G., et al. (1995) Amino acid sequence based PCR primers for amplification of rearranged human heavy and light chain immunoglobulin variable region genes. Journal of Immunological Methods, 179, 203-214. doi:10.1016/0022-1759(94)00286-6

[15] McLean, G.R., Nakouzi, A., Casadevall, A. and Green, N.S. (2000) Human and murine immunoglobulin expression vector cassettes. Molecular Immunology, 37, 837 845. doi:10.1016/S0161-5890(00)00101-2

[16] Wernette, C.M., Frasch, C.E., Madore, D., Carlone, G., Goldblatt, D., Plikaytis, B., Benjamin, W., Quataert, S.A., Hildreth, S., Sikkema, D.J., Kayhty, H., Jonsdottir, I. and Nahm, M.H. (2003) Enzyme-linked immunosorbent assay for quantitation of human antibodies to pneumococcal polysaccharides. Clinical and Diagnostic Laboratory Immunology, 10, 514-519.

[17] Mian, I.S., Bradwell, A.R. and Olson, A.J. (1991) Structure, function and properties of antibody binding sites. Journal of Molecular Biology, 217, 133-151. doi:10.1016/0022-2836(91)90617-F

[18] Russell, N.D., Corvalan, J.R., Gallo, M.L., Davis, C.G. and Pirofski, L. (2000) Production of protective human antipneumococcal antibodies by transgenic mice with 
human immunoglobulin loci. Infection and Immunity, 68, 1820-1826. doi:10.1128/IAI.68.4.1820-1826.2000

[19] Lucas, A.H., Moulton, K.D., Tang, V.R. and Reason, D.C. (2001) Combinatorial library cloning of human antibodies to Streptococcus pneumoniae capsular polysaccharides: variable region primary structures and evidence for somatic mutation of Fab fragments specific for capsular serotypes 6B, 14, and 23F. Infection and Immunity, 69, 853-864. doi:10.1128/IAI.69.2.853-864.2001

[20] Zhou, J., Lottenbach, K.R., Barenkamp, S.J., Lucas, A.H. and Reason, D.C. (2002) Recurrent variable region gene usage and somatic mutation in the human antibody response to the capsular polysaccharide of Streptococcus pneumoniae type 23F. Infection and Immunity, 70, 40834091. doi:10.1128/IAI.70.8.4083-4091.2002

[21] Reason, D.C. and Zhou, J. (2004) Correlation of antigenic epitope and antibody gene usage in the human immune response to Streptococcus pneumoniae type $23 \mathrm{~F}$ capsular polysaccharide. Clinical Immunology, 111, 132-136. doi:10.1016/j.clim.2003.12.004

[22] Zhou, J., Lottenbach, K.R., Barenkamp, S.J. and Reason, D.C. (2004) Somatic hypermutation and diverse immunoglobulin gene usage in the human antibody response to the capsular polysaccharide of Streptococcus pneumoniae Type 6B. Infection and Immunity, 72, 3505-3514. doi:10.1128/IAI.72.6.3505-3514.2004

[23] Baxendale, H.E., Johnson, M., Stephens, R.C., Yuste, J., Klein, N., Brown, J.S. and Goldblatt, D. (2008) Natural human antibodies to pneumococcus have distinctive molecular characteristics and protect against pneumococcal disease. Clinical \& Experimental Immunology, 151, 51-60. doi:10.1111/j.1365-2249.2007.03535.x

[24] Ochsenbein, A.F. and Zinkernagel, R.M. (2000) Natural antibodies and complement link innate and acquired immunity. Immunology Today, 21, 624-630. doi:10.1016/S0167-5699(00)01754-0

[25] Casali, P. and Notkins, A.L. (1989) CD5+ B lymphocytes, polyreactive antibodies and the human B-cell repertoire. Immunology Today, 10, 364-368. doi:10.1016/0167-5699(89)90268-5

[26] Berland, R. and Wortis, H.H. (2002) Origins and functions of B-1 cells with notes on the role of CD5. Annual Review of Immunology, 20, 253-300. doi:10.1146/annurev.immunol.20.100301.064833

[27] Hardy, R.R. and Hayakawa, K. (2001) B cell development pathways. Annual Review of Immunology, 19, 595621. doi:10.1146/annurev.immunol.19.1.595

[28] Mackenzie, L.E., Youinou, P.Y., Hicks, R., Yuksel, B., Mageed, R.A. and Lydyard, P.M. (1991) Auto- and polyreactivity of IgM from CD5+ and CD5- cord blood B cells. Scandinavian Journal of Immunology, 33, 329335. doi:10.1111/j.1365-3083.1991.tb01778.x

[29] Baumgarth, N., Herman, O.C., Jager, G.C., Brown, L.E., Herzenberg, L.A. and Chen, J. (2000) B-1 and B-2 cellderived immunoglobulin $\mathrm{M}$ antibodies are nonredundant components of the protective response to influenza virus infection. Journal of Experimental Medicine, 192, 271280. doi:10.1084/jem.192.2.271

[30] Boes, M., Prodeus, A.P., Schmidt, T., Carroll, M.C. and
Chen, J. (1998) A critical role of natural immunoglobulin $\mathrm{M}$ in immediate defense against systemic bacterial infection. Journal of Experimental Medicine, 188, 23812386. doi:10.1084/jem.188.12.2381

[31] Briles, D.E., Nahm, M., Schroer, K., Davie, J., Baker, P., Kearney, J. and Barletta, R. (1981) Antiphosphocholine antibodies found in normal mouse serum are protective against intravenous infection with type 3 streptococcus pneumoniae. Journal of Experimental Medicine, 153, 694-705. doi:10.1084/jem.153.3.694

[32] Ochsenbein, A.F., Fehr, T., Lutz, C., Suter, M., Brombacher, F., Hengartner, H. and Zinkernagel, R.M. (1999) Control of early viral and bacterial distribution and disease by natural antibodies. Science, 286, 2156-2159. doi:10.1126/science.286.5447.2156

[33] Baxendale, H.E. and Goldblatt, D. (2006) Correlation of molecular characteristics, isotype, and in vitro functional activity of human antipneumococcal monoclonal antibodies. Infection and Immunity, 74, 1025-1031. doi:10.1128/IAI.74.2.1025-1031.2006

[34] Romero-Steiner, S., Musher, D.M., Cetron, M.S., Pais, L.B., Groover, J.E., Fiore, A.E., Plikaytis, B.D. and Carlone, G.M. (1999) Reduction in functional antibody activity against Streptococcus pneumoniae in vaccinated elderly individuals highly correlates with decreased IgG antibody avidity [see comments]. Clinical Infectious Diseases, 29, 281-288. doi:10.1086/520200

[35] Usinger, W.R. and Lucas, A.H. (1999) Avidity as a determinant of the protective efficacy of human antibodies to pneumococcal capsular polysaccharides. Infection and Immunity, 67, 2366-2370.

[36] Sun, Y., Hwang, Y. and Nahm, M.H. (2001) Avidity, potency, and cross-reactivity of monoclonal antibodies to pneumococcal capsular polysaccharide serotype 6B. Infection and Immunity, 69, 336-344. doi:10.1128/IAI.69.1.336-344.2001

[37] Greenspan, N.S. and Cooper, L.J. (1992) Intermolecular cooperativity: A clue to why mice have IgG3? Immunology Today, 13, 164-168. doi:10.1016/0167-5699(92)90120-V

[38] Alonso de Velasco, E., Verheul, A.F., van Steijn, A.M., Dekker, H.A., Feldman, R.G., Fernandez, I.M., Kamerling, J.P., Vliegenthart, J.F., Verhoef, J. and Snippe, H. (1994) Epitope specificity of rabbit immunoglobulin G (IgG) elicited by pneumococcal type $23 \mathrm{~F}$ synthetic oligosaccharide- and native polysaccharide-protein conjugate vaccines: Comparison with human anti-polysaccharide 23F IgG. Infection and Immunity, 62, 799-808.

[39] Brezinschek, H.P., Foster, S.J., Dorner, T., Brezinschek, R.I. and Lipsky, P.E. (1998) Pairing of variable heavy and variable kappa chains in individual naive and memory B cells. Journal of Immunology, 160, 4762-4767.

[40] Bridges, S.L. Jr., Lee, S.K., Johnson, M.L., Lavelle, J.C., Fowler, P.G., Koopman, W.J. and Schroeder, H.W. Jr. (1995) Somatic mutation and CDR3 lengths of immunoglobulin kappa light chains expressed in patients with rheumatoid arthritis and in normal individuals. Journal of Clinical Investigation, 96, 831-841.

doi:10.1172/JCI118129 
[41] Baxendale, H.E., Davis, Z., White, H.N., Spellerberg, M.B., Stevenson, F.K. and Goldblatt, D. (2000) Immunogenetic analysis of the immune response to pneumococcal polysaccharide. European Journal of Immunology, 30, 1214-1223. doi:10.1002/(SICI)1521-4141(200004)30:4<1214::AID-I MMU1214>3.0.CO;2-D

[42] Wang, D., Hubbard, J.M. and Kabat, E.A. (1993) Modeling study of antibody combining sites to (alpha 1-6) dextrans. Predictions of the conformational contribution of VL-CDR3 and J kappa segments to groove-type combining sites. Journal of Biological Chemistry, 268, 20584-20589.

[43] Ichiyoshi, Y. and Casali, P. (1994) Analysis of the structural correlates for antibody polyreactivity by multiple reassortments of chimeric human immunoglobulin heavy and light chain V segments. Journal of Experimental Medicine, 180, 885-895. doi:10.1084/jem.180.3.885

[44] Casali, P. and Schettino, E.W. (1996) Structure and function of natural antibodies. Current Topics in Microbiology and Immunology, 210, 167-179. doi:10.1007/978-3-642-85226-8 17

[45] Van Esch, W.J., Reparon-Schuijt, C.C., Hamstra, H.J., van Kooten, C., Logtenberg, T., Breedveld, F.C. and Verweij, C.L. (2002) Polyreactivity of human IgG Fcbinding phage antibodies constructed from synovial fluid CD38+ B cells of patients with rheumatoid arthritis. Journal of Autoimmunity, 19, 241-250. doi:10.1006/jaut.2002.0621
[46] Schreiber, J.R., Barrus, V., Cates, K.L. and Siber, G.R. (1986) Functional characterization of human IgG, IgM, and IgA antibody directed to the capsule of Haemophilus influenzae type b. Journal of Infectious Diseases, 153, 816. doi:10.1093/infdis/153.1.8

[47] Torres, M., Fernandez-Fuentes, N., Fiser, A. and Casadevall, A. (2007) Exchanging murine and human immunoglobulin constant chains affects the kinetics and thermodynamics of antigen binding and chimeric antibody autoreactivity. PLoS One, 2, e1310. doi:10.1371/journal.pone.0001310

[48] Morelock, M.M., Rothlein, R., Bright, S.M., Robinson, M.K., Graham, E.T., Sabo, J.P., Owens, R., King, D.J., Norris, S.H., Scher, D.S., et al. (1994) Isotype choice for chimeric antibodies affects binding properties. Journal of Biological Chemistry, 269, 13048-13055.

[49] Torres, M., May, R., Scharff, M.D. and Casadevall, A. (2005) Variable-region-identical antibodies differing in isotype demonstrate differences in fine specificity and idiotype. Journal of Immunology, 174, 2132-2142.

[50] McCloskey, N., Turner, M.W., Steffner, P., Owens, R. and Goldblatt, D. (1996) Human constant regions influence the antibody binding characteristics of mouse-human chimeric IgG subclasses. Immunology, 88, 169-173. doi:10.1111/j.1365-2567.1996.tb00001.x

[51] Liu, H., Chumsae, C., Gaza-Bulseco, G., Hurkmans, K. and Radziejewski, C.H. (2010) Ranking the susceptibility of disulfide bonds in human IgG1 antibodies by reduction, differential alkylation, and LC-MS analysis. Analytical Chemistry, 82, 5219-5226. doi:10.1021/ac100575n 